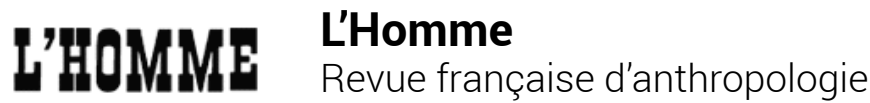

163 | juillet-sptembre 2002

De la légende au mythe. Parole, langue et pensée

\section{Anne Raulin, L'Ethnique est quotidien. Diasporas, marchés et cultures métropolitaines}

Paris, L'Harmattan, 2000, 229 p., bibl., index, carte («Connaissance des hommes »)

\section{David Lepoutre}

\section{(2) OpenEdition}

12 Journals

Édition électronique

URL : http://journals.openedition.org/lhomme/12721

DOI : 10.4000//homme.12721

ISSN : 1953-8103

Éditeur

Éditions de l'EHESS

Édition imprimée

Date de publication : 21 juin 2002

Pagination : 298-299

ISBN : 2-7132-1771-7

ISSN : 0439-4216

Référence électronique

David Lepoutre, «Anne Raulin, L'Ethnique est quotidien. Diasporas, marchés et cultures métropolitaines », L'Homme [En ligne], 163 | juillet-sptembre 2002, mis en ligne le 10 juillet 2007, consulté le 22

septembre 2020. URL : http://journals.openedition.org//homme/12721 ; DOI : https://doi.org/10.4000/ Ihomme.12721

Ce document a été généré automatiquement le 22 septembre 2020.

(c) École des hautes études en sciences sociales 


\section{Anne Raulin, L'Ethnique est quotidien. Diasporas, marchés et cultures métropolitaines}

Paris, L'Harmattan, 2000, 229 p., bibl., index, carte (« Connaissance des hommes »)

\section{David Lepoutre}

1 À UNE ÉPOQUE où les conflits de classes semblent disparaître du champ politique et de la conscience collective au profit d'une ethnicisation, voire d'une racialisation de la perception des différences sociales, l'ouvrage d'Anne Raulin aborde un sujet très actuel qui est celui du marché des produits «ethniques» dans les grandes métropoles. L'étude, centrée sur l'agglomération parisienne, concerne d'une part le secteur des commerces ethniques, tenus par des minorités étrangères, d'autre part la consommation des produits exotiques ou étrangers par ces mêmes minorités et aussi par les populations autochtones.

Le livre aborde des thèmes divers et variés. Le premier chapitre traite des causes de l'implantation d'un quartier asiatique à forte dominante commerciale dans le triangle de Choisy du XIII arrondissement et analyse son histoire et son évolution ultérieure. Les chapitres II et III décrivent et comparent les combinaisons variées des éléments d'origines étrangères et de tradition autochtone, d'abord dans les commerces maghrébins (épiceries, marchands de fruits et légumes, café-hôtel et restaurants), ensuite dans les restaurants chinois. Ces combinaisons contribuent à la formation et à l'évolution d'un certain type de paysage urbain, ici conçu comme "théâtre ». Le chapitre IV porte sur les cérémonies du Nouvel an chinois à Paris, dans le XIII ${ }^{e}$ arrondissement, et sur les autres implantations asiatiques de la capitale. Les pratiques festives, ainsi que leur intrication avec les fêtes de fin d'année du calendrier chrétien, sont étudiées aussi bien dans les espaces publics que dans les espaces domestiques. Le chapitre $\mathrm{V}$ aborde la question des mariages maghrébins et asiatiques parisiens, du point de vue des traditions de costumes et de vêtements de mariés, en analysant les effets du « décentrement culturel » sur les options et les choix retenus. Enfin, les chapitres VI, 
VII et VIII ont respectivement pour objets les achats vestimentaires, les formes d'approvisionnement alimentaire et les consommations de biens médiatiques des minorités maghrébines et chinoises. Sont notamment analysées dans cette dernière partie les différentes formes de syncrétisme qui caractérisent ces consommations culturelles et leurs variations en fonction des différentes populations concernées.

3 Anne Raulin rend bien compte, tant du côté des marchands que du côté des acheteurs et consommateurs, de la complexité des pratiques, des combinatoires culturelles diverses et variées, de la multiplicité des références, des souplesses adaptatives des acteurs et de la variation dans le temps, ou d'une population à une autre, en fonction des contextes et des histoires migratoires. Les perspectives sont d'autant plus intéressantes que les pratiques de consommation sont devenues, comme on le sait, un phénomène culturel majeur des sociétés contemporaines occidentalisées. L'enquête, qui procède d'une "démarchemulticentrée ", est toujours comparative et fait varier les échelles.

4 Le principal défaut de l'ouvrage résulte sans doute de son mode de fabrication. Comme l'auteur l'indique dans l'introduction, il a été construit à partir d'une somme d'articles issus de recherches effectuées depuis une quinzaine d'années, et qui correspondent à peu près aux huit chapitres évoqués ci-dessus. Un travail de présentation d'une part, et de réflexion d'ensemble et de théorisation d'autre part, a été mené au terme de cette somme de publications. Mais l'ordonnancement et l'articulation des chapitres n'aboutissent pas véritablement à une démonstration d'ensemble. La problématisation globale fait donc un peu défaut.

5 Peut-être cela a-t-il empêché Anne Raulin de creuser certaines pistes d'analyse, notamment sur le «besoin d'ethnicité » dans la société française. Dans l'introduction, elle évoque un phénomène marquant et contemporain, qui est celui de la consommation "superficielle » d'ethnicité par les membres des classes moyennes et supérieures autochtones, par exemple ceux, bien représentés dans les professions artistiques, qui choisissent de résider dans des quartiers à forte mixité ethnique. Ce sujet, très intéressant, n'est cependant pas véritablement traité. Or, ce «besoin d'ethnicité " se développe comme par hasard dans une période où les rapports de classes s'ethnicisent et où les couches dominantes font tout leur possible pour "débarrasser" les centres-villes des fractions les plus voyantes et les moins présentables des classes populaires, fréquemment confondus avec les populations d'origine étrangère, ou encore s'évertuent à fuir le contact véritable - par le biais, par exemple, de la dérogation scolaire - avec les populations issues de l'immigration. D'une façon générale, la dimension de classe des phénomènes semble avoir été largement occultée dans cet ouvrage. On sait par exemple que, globalement, les populations réfugiées asiatiques n'ont pas les mêmes origines sociales et n'appartiennent pas aux mêmes milieux socio-professionnels que les immigrés maghrébins. Cela joue certainement sur les modes de consommation, y compris de consommation ethnique. Pourtant, Anne Raulin a su par ailleurs très bien prendre en compte des différences culturelles, de sexes, de génération et d'âge, qui expliquent également certaines différences d'attitude.

6 Gageons donc, pour finir, que les variations sociales des consommations et le besoin contradictoire d'ethnicité des classes moyennes urbaines feront de sa part l'objet de travaux et de publications futures. 